\title{
CORRELATION BETWEEN CENTRAL CORNEAL THICKNESS AND DEGREE OF HYPEROPIA
}

\author{
By

\section{Mahmoud Mohamed Ismail, Nour El-Din Abd Al-Hamid Abd Al- Halim and Amr Abd Allah Mahmoud El-Sheikh} \\ Ophthalmology Department, Faculty of Medicine, Al-Azhar University, Cairo
}

\begin{abstract}
Background: The transparent cornea forms the anterior portion of the outer casing of the eye and has the dual functions of protecting the inner contents of the eye as well as providing about two thirds of the eye's refractive power.
\end{abstract}

Objectives: The purpose of this study was to evaluate the correlations between central corneal thickness and degree of hyperopia in adult populations .

Patients and Methods: This was a prospective cross-sectional, observational study conducted in Ophthalmology Department, Al-Azhar University Hospitals, were divided equally into two groups according to their ages : Group 1 included patients with age range from 20-37, and group 2 consisted of patients aged 42-56. Each group contained 15 males and 15 females. Approval of Al-Azhar University ethics committee was obtained for the study. The nature and methodology involved in the study were explained to the patient and informed consent were obtained.

Results: The results of the current study showed that the range of central corneal thickness (CCT) in group 1 was 512-631 um with mean $\pm \mathrm{SD}$ of $570.87 \pm 25$.31. In group 2, CCT ranged from 530 to 694 um with mean $\pm \mathrm{SD}$ of $567.37 \pm 30.89$. In addition, there was no significant correlation between CCT and age in either group. The present study delineated that the mean \pm SD of refraction of both groups was $3.91 \pm 1.20$ and 3.17 \pm 1.01 respectively. The median of cylinder in both groups was -1.5 and -1 respectively, and the median of axis was 75 and 92.5 respectively. Significant association between CCT and refraction could not be noticed in both groups besides the non-significant association between CCT with either cylinder or axis in them.

Conclusion: Among adult subject with age range 20-60, central corneal thickness did not correlate with age change. Degree of hyperopia did not affect central corneal thickness of adult subjects. Central corneal thickness did not correlate with degree of intraocular pressure in hyperopic adults with normal IOP.

Keywords: Central Corneal Thickness, Hyperopia.

\section{INTRODUCTION}

The cause is an imperfection of the eyes. Often it occurs when the eyeball is too short, or the lens or cornea is misshapen. Risk factors include a family history of the condition, diabetes, certain medications, and tumors around the eye. It is a type of refractive error. Diagnosis is based on an eye exam (Kaiser Peter et al., 2014). Hyperopia primarily affects young children, with rates of $8 \%$ at 6 years and $1 \%$ at 15 years. It then becomes more common again after the age of 40 , affecting about half of people (Castagno et al., 2014).

Central corneal thickness is an important indicator of health status of the cornea especially of corneal endothelial pump function, it is also has value in refractive surgery (Shalini et al., 2017). 
CCT can be assessed by means of many instruments, including specular microscopy, ultrasound pachymetry, ultrasound biomicroscopy (UBM), slitscanning corneal topography, the Scheimpflug system (Pentacam), optical biometry, and optical coherence tomography (OCT) (Al-Mezaine et al., 2008).

The Pentacam combines a rotating Scheimpflug camera with a static camera to acquire multiple photographs of the anterior eye segment. The Scheimpflug camera rotates along with a monochromatic slit-light source around the optical axis to obtain the slit images. This rotating system performs a corneal scan from zero to 180 and each of the photographs is an image of the cornea at a specific angle. The static camera is placed in the center to detect the pupils contours and control fixation. Analyses of corneal pachymetry, corneal wavefront aberrations, densitometry and the complete anterior chamber are also provided by the Pentacam (Wegener and Laser-Junga, 2009).

The aim of this study was to evaluate the correlations between central corneal thickness and degree of hyperopia in adult populations presenting to the outpatient ophthalmology clinics of Al-Azhar University Hospitals.

\section{PATIENTS AND METHODS}

This was a prospective cross-sectional, observational study conducted in Ophthalmology Department, Al-Azhar University Hospitals, cairo, Egypt. A total of 60 eyes were recruited from Al-Azhar University Hospitals outpatient clinic. They were divided equally into two equal groups according to their age; Group 1 included patients with age range from 2037 and Group 2 consisted of patients aged 42-56. Each group contained 15 males and 15 females.

Approval of Al-Azhar University ethics committee was obtained for the study. The nature and methodology involved in the study were explained to the patient and informed consents were obtained.

\section{Inclusion criteria:}

- Errors of refraction: +2D: +6D and cylinder less than 2D.

- Healthy and clear cornea.

\section{Exclusion criteria:}

- Patients below 20 or above 60 .

- Errors of refraction below $+2 \mathrm{D}$ or above $+6 \mathrm{D}$.

- Unhealthy and opacified cornea.

- Glaucomatous patients.

- Patients with previous corneal surgeries.

Each Patient was subjected to the following:

- History taking.

- BCVA (using Snellen's visual acuity chart).

- IOP measurement (using Goldmann applanation tonometer).

- Slit lamp examination of the anterior segment.

- Auto refractometer testing for refraction measurement, KR-800; Topcon Medical Systems, Inc., Fukuoka, Japan was used.

- Pentacam Corneal Topography for the assessment of CCT. At the time of 
study, the machine used Pentacam Software V1.20r87.

\section{Statistical analysis:}

Data were collected, revised and entered to the Statistical Package for Social Science (SPSS) program (version 23; Inc., Chicago. IL). The qualitative data were presented as numbers and percentages and compared between the two groups using Chi-square test. While quantitative data were presented as mean, standard deviations and ranges and compared between the two studied groups using Independent t-test when the data were parametric and Mann-Whitney test when the data were non parametric. Also Spearman correlation coefficients were used to assess the correlation between two quantitative variables in the same group. The confidence interval was set to $95 \%$ and the margin of error accepted was set to $5 \%$. So, the p-value was considered significant at the level of $<0.05$.

\section{RESULTS}

Age of group I was ranged from 20 to 37 years with mean \pm SD of $27.37 \pm 5.80$, while in group II age ranged from 42 to 56 year with mean $\pm \mathrm{SD}$ of $47.97 \pm 4.04$. The two groups were matched in gender which was $50 \%$ males and $50 \%$ females (Taele $1)$.

Table (1): Age and gender distribution among patients of group I

\begin{tabular}{|l|l|c|c|}
\hline \multirow{2}{*}{ Parameters } & \multirow{2}{*}{ Groups } & Group I & Group II \\
\cline { 3 - 4 } Age & Mean \pm SD & No. $=\mathbf{3 0}$ & No. $=\mathbf{3 0}$ \\
\cline { 2 - 4 } & Range & $27.37 \pm 5.80$ & $47.97 \pm 4.04$ \\
\hline \multirow{2}{*}{ Gender } & Female & $15(50.0 \%)$ & $42-56$ \\
\cline { 2 - 4 } & Male & $15(50.0 \%)$ & $15(50.0 \%)$ \\
\hline
\end{tabular}

There was no statistically significant difference found between the two studied groups regarding degree of hyperopia,
CCT, affected eye and IOP with p-value > 0.05 (Table 2). 
Table (2): Refraction, cylinder, axis CCT, eye affected and IOP level among patients of group I

\begin{tabular}{|c|c|c|c|c|c|c|}
\hline \multirow{2}{*}{\multicolumn{2}{|c|}{ Parameters $\quad$ Groups }} & \multirow{2}{*}{$\begin{array}{l}\text { Group I } \\
\text { No. }=30 \\
\end{array}$} & \multirow{2}{*}{$\begin{array}{c}\text { Group II } \\
\text { No. }=\mathbf{3 0}\end{array}$} & \multirow{2}{*}{ Test value } & \multirow{2}{*}{ P-value } & \multirow{2}{*}{ Sig. } \\
\hline & & & & & & \\
\hline \multirow{2}{*}{ Refraction } & Mean \pm SD & $3.91 \pm 1.20$ & $3.49 \pm 1.06$ & \multirow{2}{*}{$1.422^{\bullet}$} & \multirow{2}{*}{0.161} & \multirow{2}{*}{ NS } \\
\hline & Range & $2-6$ & $2-5.5$ & & & \\
\hline \multirow{2}{*}{ Cylinder } & Median (IQR) & $-1.5(-2--0.5)$ & $-1(-1.63--0.5)$ & \multirow{2}{*}{$-1.028^{\neq}$} & \multirow{2}{*}{0.304} & \multirow{2}{*}{ NS } \\
\hline & Range & $-2--0.5$ & $-2--0.25$ & & & \\
\hline \multirow{2}{*}{ Axis } & Median (IQR) & $75(20-155)$ & $92.5(52.5-102.5)$ & \multirow{2}{*}{$-0.842^{\neq}$} & \multirow{2}{*}{0.400} & \multirow{2}{*}{ NS } \\
\hline & Range & $10-175$ & $10-180$ & & & \\
\hline \multirow{2}{*}{ CCT } & Mean \pm SD & $570.87 \pm 25.31$ & $567.37 \pm 30.89$ & \multirow{2}{*}{$0.480^{\bullet}$} & \multirow{2}{*}{0.633} & \multirow{2}{*}{ NS } \\
\hline & Range & $512-631$ & $530-649$ & & & \\
\hline \multirow{2}{*}{ Eye } & OD & $16(53.3 \%)$ & $15(50.0 \%)$ & \multirow{2}{*}{$0.067 *$} & \multirow{2}{*}{0.796} & \multirow{2}{*}{ NS } \\
\hline & OS & $14(46.7 \%)$ & $15(50.0 \%)$ & & & \\
\hline \multirow{2}{*}{ IOP } & Mean \pm SD & $12.20 \pm 1.40$ & $12.77 \pm 1.59$ & \multirow{2}{*}{$-1.465^{\circ}$} & \multirow{2}{*}{0.148} & \multirow{2}{*}{ NS } \\
\hline & Range & $10-16$ & $10-16$ & & & \\
\hline
\end{tabular}

There was no statistically significant correlation found between CCT and degree of hyperopia in group I and also in group II with p-value > 0.05 (Table 3 ).

Table (3): Correlation of CCT with the other studied parameters among patients of group I and group II

\begin{tabular}{|l|c|c|c|c|}
\multirow{2}{*}{ Parameters } & \multicolumn{4}{|c|}{ CCT } \\
\cline { 2 - 5 } & \multicolumn{2}{|c|}{ Group I } & \multicolumn{2}{c|}{ Group II } \\
\cline { 2 - 5 } Refraction & r & P-value & r & P-value \\
\hline Cylinder & 0.165 & 0.382 & 0.067 & 0.727 \\
\hline Axis & -0.308 & 0.153 & -0.129 & 0.547 \\
\hline
\end{tabular}

\section{DISCUSSION}

For a healthy cornea, the Central Corneal Thickness (CCT) varies between $0.49 \mathrm{~mm}$ to $0.57 \mathrm{~mm}$. CCT has a very important role in glaucoma. CCT results in under estimation of the true Intraocular Pressure (IOP) and thicker CCT results in over estimation of IOP (Kalikivayi et al., 2018). In addition, CCT is important in assessing eligibility in refractive surgery candidates where it is used to exclude those in danger of postoperative ectasia (Hashmani et al., 2017). Thus, accurate measurement of CCT is an essential procedure for patients undergoing LASIK, glaucoma treatment along with diagnosing corneal ectasia conditions, it is essential to know the normative data of the population 
to further plan the clinical treatment for a given patient. Documented differences between various refractive groups may contribute to the ongoing research in the field of glaucoma and LASIK (Kalikivayi et al., 2018).

Given that, this study was designed to evaluate the correlations between central corneal thickness and degree of hyperopia in adult populations.

This study enrolled a total of 60 eyes divided equally into two groups of patients according to their age. Group 1 included 30 eyes of patients with age range from 20-37 and mean \pm SD of 27.37 \pm 5.80 . Group 2 consisted of 30 patients aged 42-56 with mean \pm SD of $47.97 \pm$ 4.04. Each group contained 15 males and 15 females.

The results of the current study showed that the range of CCT in group 1 was 512631 with mean \pm SD of $570.87 \pm 25.31$. In group 2 the CCT ranged from 530 to 694 with mean \pm SD of $567.37 \pm 30.89$. In addition, there was no significant correlation between CCT and age in either group.

Valdez-Garc?a et al. (2017) described the distribution of the CCT measurements on a healthy Hispanic sample population and its correlation with age. There was no correlation registered between CCT and the age when analyzed with the Anderson-Darling Shapiro-Wilk, and Kolmogorov-Smirnov , A positive correlation between CCT and age was observed in the group $<20$ years.

The present study delineated that the mean \pm SD of refraction of both groups was $3.91 \pm 1.20$ and $3.17 \pm 1.01$ respectively. The median of cylinder in both group was $(-1.5,-1$ respectively) and the median of axis was $(75,92.5)$ respectively. Significant association between CCT and refraction could not be noticed in any group besides the nonsignificant association between CCT with either cylinder or axis in both groups.

Similarly, Prasad et al. (2011) studied the CCT in a large population of normal eyes undergoing refractive surgery to assess the relationship of 2 variables, age and refraction, with CCT. They found that CCT did not correlate with either age or refraction.

By the same way, Kalikivayi et al. (2018) compared the central corneal thickness between myopes, hyperopes and emmetropes of different age groups. They reported that there were no statistically significant differences between the CCT's of myopic, hyperopic and emmetropic eyes for different age groups and no significant correlations between CCT and the amount of spherical equivalent in hyperopes and myopes.

Koucheki et al. (2010) evaluated the correlation of CCT with refractive error in a group of patients eligible for laser keratorefractive surgery. They noticed that refractive indices (Sphere, cylinder and axis) did not show any significant correlation with CCT in the whole group or different subgroups.

Chen et al. (2009) examined the relationship between $\mathrm{CCT}$, refractive error, corneal curvature, anterior chamber depth and axial length in normal Taiwanese Chinese adults. Their results confirmed that CCT was not associated with refractive error, corneal curvature, anterior chamber depth and axial length. 
Thus CCT is an independent factor unrelated to other ocular parameters.

Iyamu et al. (2013) studied the relationship between CCT and axial length (AL) in adult Nigerians. The average CCT and AL were 547.0 \pm 29.5 $? \mathrm{~m}$ and $23.5 \pm 0.70 \mathrm{~mm}$, respectively and the association between CCT and AL was not significant.

In a cross sectional observational study of Abbas et al. (2018), showed that no significant relation was found between refractive errors and $\mathrm{CCT}$.

The difference in results among studies could be related to different sample sizes, different devices used to measure CCT, or human error in obtaining accurate results.

Regarding IOP in the present study, it was nearly the same in both age groups. Also, there was no significant correlation between CCT and IOP in both groups.

Similarly, the study of Iyamu and Osuobeni (2012) showed no correlation between CCT and IOP. In addition, CCT was not significantly influenced by corneal curvature and corneal diameter. The study of Inceoğlu et al. (2018) confirmed that corneal-compensated IOP (IOPcc) was independent from CCT.

However, Vijaya et al. (2010) reported a positive association between CCT and intraocular pressure among Indian population. Also Kamath et al. (2017) found that IOP was higher in normal subjects who had thicker corneas as measured by Goldmann Applanation tonometry. Cairns et al. (2019) reported a positive correlation between CCT and IOP in a cohort of keratoconic patients.
The study of Avitabile et al. (2010) stated that IOP values were correlated with CCT but the discrepancy between RT and GAT values was not related to CCT and was related to the refractive error.

The different heterogeneous reports of Chua et al. (2014); Farvardin et al. (2017) that CCT among hyperopic patients did not show any significant correlation with age, indices of refraction and IOP.

In the same point of view, Gros-Otero et al., (2011) found that the mean central corneal thickness was $548.21 ? \mathrm{~m}$ with no statistical association was found between central corneal thickness values and variables of age, refractive error, axial length and gender.

Ismaili et al. (2019) found no correlation with age. However, they reported a negative correlation between the CCT and the IOP.

Sng et al. (2016) revealed a significant association between increased CCT and younger age, male sex, and higher IOP but not glaucoma.

The results of Hawng et al. (2012) also showed that in univariate analysis, a thicker CCT was associated with a higher IOP, a longer axial length (AL), and a younger age but in multivariate analysis there was no significant correlation between CCT and AL.

Linke et al. (2011) evaluated the relationship between the thinnest point in corneal thickness and the refractive state, keratometry, age, sex, and the ocular size among refractive surgery candidates including hyperopic, myopic eyes and high astigmatism. They found that refractive state, mean keratometry, and 
age had a statistically significant on the thinnest point in corneal thickness. Sex and the ocular size had no effect.

Lanza et al. (2015) compared corneal pachymetry values measured by three different optical devices: Orbscan II, Pentacam HR and Sirius in healthy eyes. They delineated that the measurement of CCT by Sirius and Pentacam HR provides similar results. By contrast, the results obtained by Orbscan II are different from those obtained from both Sirius and Pentacam HR.

It is mandatory to report the limitation of the current study which included small sample size. The study indeed did not include all age groups and did not assess the difference in CCT according to gender.

\section{CONCLUSION}

Among adult subject with age range 20-60, central corneal thickness did not correlate with age change. Degree of hyperopia did not affect central corneal thickness of adult subjects. Central corneal thickness did not correlate with degree of intraocular pressure in hyperopic adults with normal IOP.

\section{REFERENCES}

1. Abbas MA and Alhammami HA (2018): Correlation between Refractive Error and Corneal Thickness in a sample of Iraqi Population with a Wide Range of Ametropia. Karbala J Med, 11: 4032 4038 .

2. Al-Mezaine HS, Al-Amro SA, Kangave D, Sadaawy A, Wehaib TA, Al-Obeidan $S$ (2008): Comparison between central corneal thickness measurements by oculus pentacam and ultrasonic pachymetry.
International Ophthalmology, 28(5): 333338 .

3. Avitabile $T$, Longo A, Rocca $D$, Amato R, Gagliano $C$ and Castaing $M$ (2010): The influence of refractive errors on IOP measurement by rebound tonometry (ICare) and Goldmann applanation tonometry. Graefe's Arch Clin Exp Ophthalmology, 248: 585-591.

4. Cairns R, Graham K, O'Gallagher M and Jackson AJ (2019): Intraocular pressure (IOP) measurements in keratoconic patients: Do variations in IOP respect variations in corneal thickness and corneal curvature? Contact Lens and Anterior Eye, 42(2):216-219.

5. Castagno VD, Fassa AG, Carret ML, Vilela MA and Meucci RD (2014): Hyperopia: a meta-analysis of prevalence and a review of associated factors among school-aged children. BMC Ophthalmology, 14: 163.

6. Chen MJ, Liu YT, Tsai CC, Chen YC, Chou CK and Lee SM (2009): Relationship between central corneal thickness, refractive error, corneal curvature, anterior chamber depth and axial length. Journal of the Chinese Medical Association, 72(3):133-137.

7. Chua J, Tham YC, Liao J, Zheng Y, Aung T, Wong TY and Cheng CY (2014): Ethnic Differences of Intraocular Pressure and Central Corneal Thickness. Ophthalmology, 121: 2013-2022.

8. Chung HJ and Park CK (2016): The Distinct Biometric Features of High Myopia Compared to Moderate Myopia. Curr Eye Res, 41: 1580-1583.

9. Dua HS, Faraj LA, Branch MJ, Yeung AM, Elalfy MS, Said DG, Gray T, Lowe J (2014): The collagen matrix of the human trabecular meshwork is an extension of the novel pre-Descemet's 
layer (Dua's layer) Br. J. Ophthalmol., 98: 691-697.

10. Farvardin M, Heidary F, Sayehmiri K, Gharebaghi R and Behrooz MJ (2017): A Comprehensive Meta-analysis on Intra Ocular Pressure and Central Corneal Thickness in Healthy Children. Iran J Public Health, 46: 724-732.

11. Gros-Otero J, Arruabarrena-S?nchez $C$ and Teus $M$ (2011): Central corneal thickness in a healthy Spanish population. Arch la Soc Espa?ola Oftalmol. English Ed; 86: 73-76.

12. Hashmani N, Hashmani S, Hanfi A, Ayub M, Saad CM, Rajani H, Muhammad MG and Aziz M (2017): Effect of age, sex, and refractive errors on central corneal thickness measured by Oculus Pentacam®. Clin Ophthalmol,11: 1233-1238.

13. İnceoğlu N, Emre $S$ and Ulusoy MO (2018): Investigation of corneal biomechanics at moderate to high refractive errors. Int Ophthalmol, 38: 1061-1067.

14. Ismaili M, Kaçaniku G, Spahiu K and Hoxha G (2019): Determination of Central Corneal Thickness in Patients with Refractive Anomalies and Emmetropy. Open J Ophthalmol; 09: 3546.

15. Iyamu E, Iyamu JE, Amadasun G (2013): Central corneal thickness and axial length in an adult Nigerian population. J Optom, 6: 154-160.

16. Iyamu E and Osuobeni E (2012): Age, gender, corneal diameter, corneal curvature and central corneal thickness in Nigerians with normal intra ocular pressure. J Optom; 5: 87-97.

17. Kaiser Peter $K$, Friedman Neil $J$ and Roberto P (2014): The Massachusetts Eye and Ear Infirmary Illustrated Manual of Ophthalmology E-Book. Elsevier Health Sciences, p. 541.

18. Kalikivayi L, Ratheesan $K$ and Kalikivayi V (2018): Comparison of central corneal thickness in myopes, hyperopes and emmetropes of different age groups. J Clin Ophthalmol; 02, Clinical Ophthalmology, 2.2.96-100.

19. Kamath $M$, George G, D'souza $S$, Kamath G, Kamath $A$ and Pai $S$ (2017): Determining the correlation between central corneal thickness and intraocular pressure in a normal indian population. Orig Res Artic J Evol Med Dent Sci. 6: 3619-36230.

20. Koucheki B, Mehravaran S and Hashemi H (2010): Correlation between central corneal thickness and refractive indices in a laser refractive surgery population. Iran J Ophthalmol. 22: 43-48.

21. Lanza M, Paolillo E, Gironi Carnevale UA, Lanza A, Irregolare C, Mele L and Bifani M (2015): Central corneal thickness evaluation in healthy eyes with three different optical devices. Contact Lens Anterior Eye, 38: 409-413.

22. Linke SJ, Steinberg J, Eddy MT, Richard $G$ and Katz T (2011): Relationship between minimum corneal thickness and refractive state, keratometry, age, sex, and left or right eye in refractive surgery candidates. J Cataract Refract Surg, 37: 2175-2180.

23. Muthu Krishnan V, Jayalatha $K$ and Vijayakumar C (2019): Correlation of Central Corneal Thickness and Keratometry with Refraction and Axial Length: A Prospective Analytic Study Cureus, 11: e3917.

24. Mwanza JC, Tulenko SE, Budenz DL, Mathenge E, Herndon LH, Kim HY, Hall A, Hay-Smith G, Spratt A and Barton K (2018): Longitudinal Change in Central Corneal Thickness in the Tema 
Eye Survey. Am J Ophthalmol, 186: 1018.

25. Prasad A, Fry K, Hersh PS (2011): Relationship of Age and Refraction to Central Corneal Thickness. Cornea, 30: 553-555.

26. Shalini M, Anand A, Tanuj D, Vanathi $M$ and Anita $P$ (2017): Pachymetry: A Review. DOS Times, 12(10): 19-23.

27. Sng C, Barton K, Kim H, Yuan S and Budenz DL (2016): Central Corneal Thickness and its Associations With Ocular and Systemic Factors in an Urban West African Population. Am J Ophthalmol, 169. 268-275.

28. Solu T, Baravaliya P, Patel I, Kamble S, Savaliya C and Golakiya B (2016): Correlation of Central Corneal Thickness and Axial Length in Myopes, Emmetropes, and Hypermetropes. Int J Sci Study, p.12.
29. Valdez-Garc 2 JE, HernandezCamarena JC, Lozano-Ram?rez JF, Zavala J, Loya-Garc $\mathbf{A}$ and MerayoLloves J (2017): Correlation of age, corneal curvature and spherical equivalent with central corneal thickness. Rev Mex Ophalmology, 91: 172-176.

30. Vijaya L, George R, Arvind H, Ramesh SV, Baskaran M, Raju P, Asokan R and Velumuri L (2010): Central Corneal Thickness in Adult South Indians. Ophthalmology, 117: 700-704.

31. Wegener A and Laser-Junga $H$ (2009): Photography of the anterior eye segment according to Scheimpflug's principle: options and limitations - a review. Clinical Experiment Ophthalmol. 37(1):144-54. 


\section{الإرتباط بين سمك القرنية المركزى ودرجة طول النظر}

محمود محمد اسماعيل، نور الدين عبد الحميد عبد الحليم، عمرو عبدالله محمود الثيخ

$$
\text { قسم طب وجراحة العين، كلية الطب، جامعة الأزهر، القاهرة }
$$

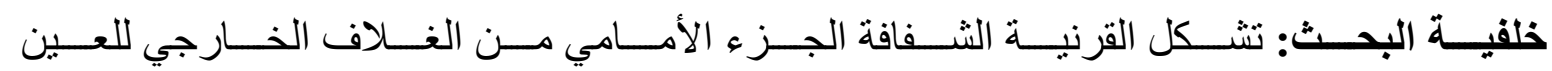

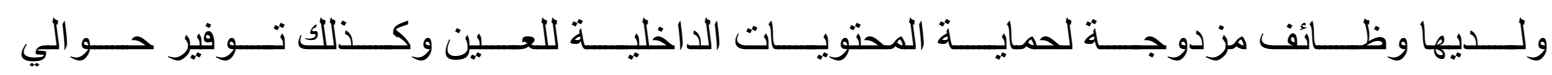
ثلثي قوة انكسار العين.

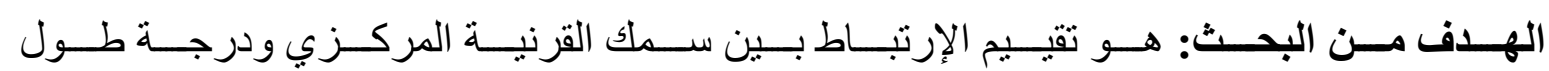

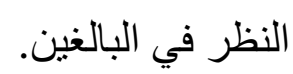

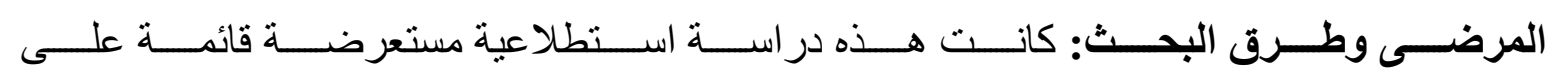

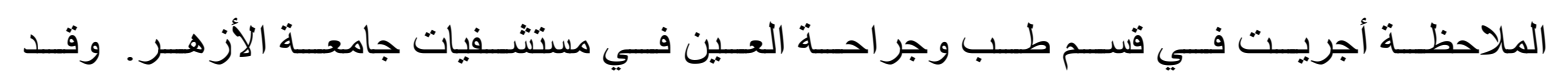

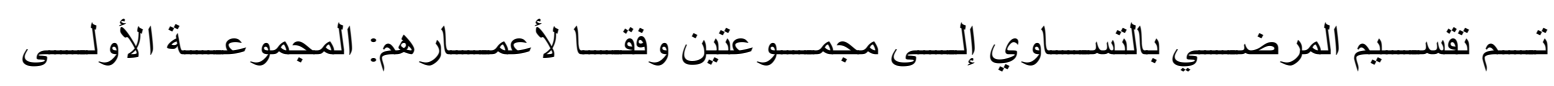

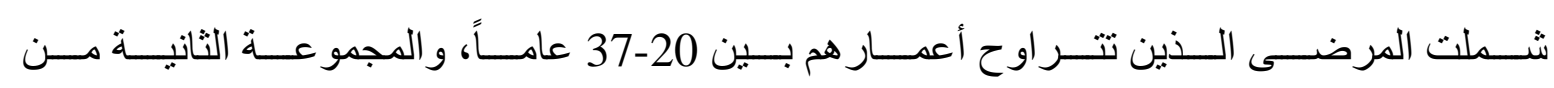

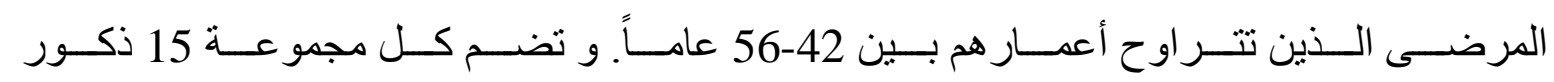

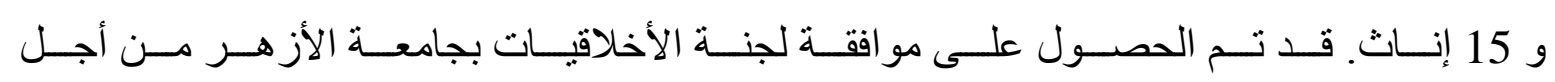

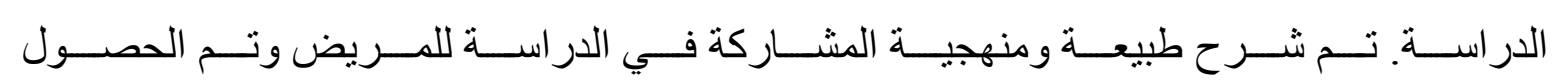
على مو افقة مستنيرة.

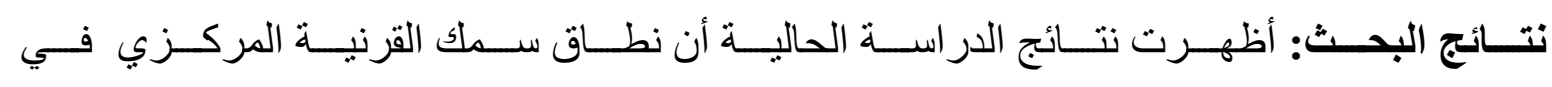

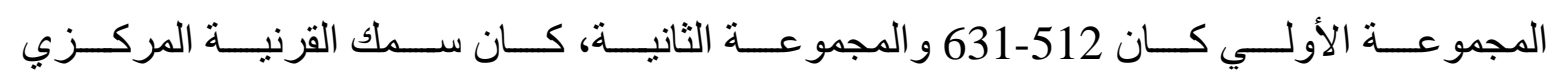

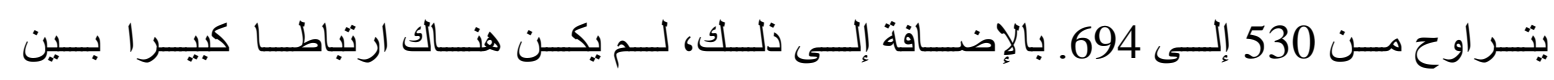

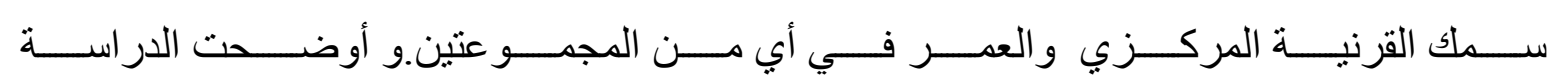

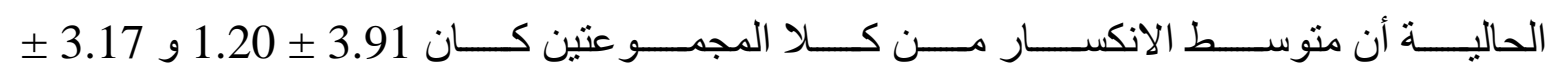

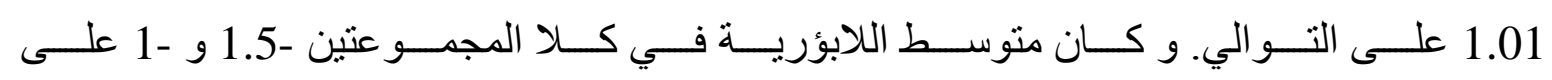

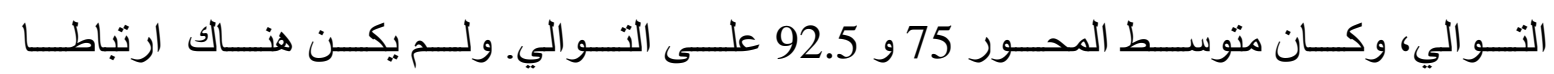

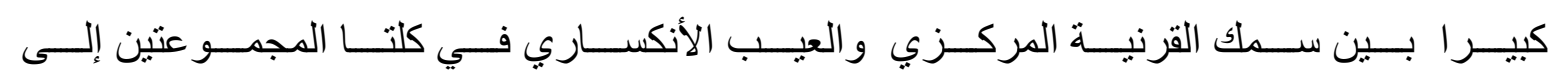

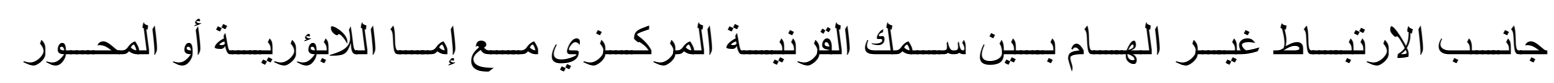


CORRELATION BETWEEN CENTRAL CORNEAL THICKNESS AND...

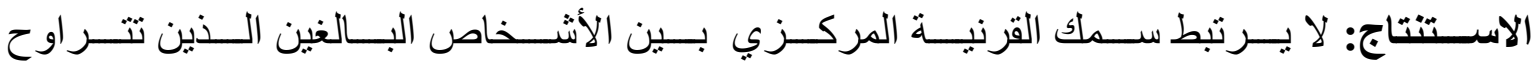

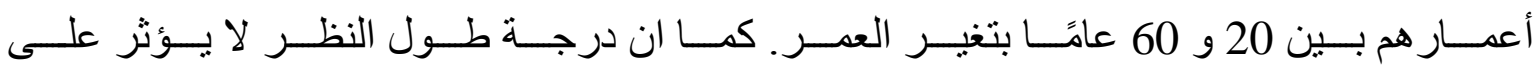

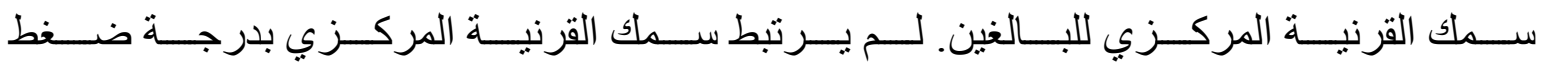
العين الطبيعي في مرضي طول النظر البالغين. 